\title{
A utilização da Escala de Desenvolvimento Motor (EDM) e a sua aplicação na fase escolar: uma realidade brasileira?
}

\author{
Matheus Martins Luz ${ }^{1}$ \\ Carlos Alexandre Felício Brito ${ }^{2}$ \\ Jessica Natacha Ferreira Batista ${ }^{3}$ \\ Pâmella Moura Lourenço ${ }^{4}$
}

\begin{abstract}
Resumo
A organização dos movimentos ao longo do tempo é um processo sequencial relacionado à idade cronológica, com interaçáo entre a tarefa motora, limites biológicos e o seu meio ambiente. O objetivo desta pesquisa foi analisar como está sendo aplicada a Escala de Desenvolvimento Motor (EDM), proposta por Neto (2002), em escolares brasileiros. Trata-se de um estudo qualitativo, do tipo descritivo, com delineamento do tipo revisão de literatura (revisão sistemática). Pode-se observar que a maioria dos estudos pesquisados é proveniente da região Sul. Foi possível perceber a importância de priorizar a prática de uma modalidade esportiva no âmbito escolar, uma vez que os estudos que apresentaram os melhores resultados estavam associados a projetos de atividade física extracurricular. Parece que a escala está sendo aplicada de forma fragmentada, não englobando completamente todos os aspectos motores dos escolares. Provavelmente, pelo curto período de tempo disponível para coleta de dados e aplicação no âmbito escolar.
\end{abstract}

Palavras-chaves: Escala de Desenvolvimento Motor. Escola. Brasil.

\begin{abstract}
The organization of movements over time is a sequential process related to chronological age, with interaction between the motor task, biological limits and its environment. The aim was to analyze how the Motor Development Scale (MDS), proposed by Neto (2002), in Brazilian schoolchildren is being applied. This is a qualitative, descriptive study, with a literature review design (systematic review). It can be observed that most of the studies studied come from the South region. It was possible to perceive the importance of prioritizing the practice of a sports modality in the school environment, since the studies that presented the best results were associated to physical activity projects. It seems that the scale is being applied in a fragmented way, not completely encompassing all the motor aspects of the students. Probably, for the short time available for data collection and application in the school setting.
\end{abstract}

Keywords: Motor Development Scale (MDS). School. Brazil.

\footnotetext{
${ }^{1}$ Graduado em Educação Física - Licenciatura - pela Universidade Municipal de São Caetano do Sul - USCS. E-mail: matheusluzworks@gmail.com 2 Doutorado em Educação Física pela Universidade Estadual de Campinas. Mestrado em Educação Física pela Universidade Estadual de Campinas. Graduação em Licenciatura Plena em Educação Física pela Faculdade de Educação Física de Santo André. Atualmente é professor na Escola da Saúde - Educação Física - e do Mestrado Profissional Inovação em Ensino Superior em Saúde na Universidade Municipal de São Caetano do Sul. E-mail: brito-ca@uol.com.br

3 Graduada em Educaçấo Física - Licenciatura - pela Universidade Municipal de São Caetano do Sul - USCS. E-mail: jehbaiarina2009@hotmail.com

${ }^{4}$ Graduada em Educação Física - Licenciatura - pela Universidade Municipal de São Caetano do Sul - USCS. E-mail: mila_2201@hotmail.com
} 
Introdução

O entendimento e a compreensáo do fenômeno do crescimento e do desenvolvimento motor, entre os pesquisadores nacionais e internacionais, tem uma história de mais de um século, porém, no Brasil, esse interesse se dá principalmente na década de 1980 (1988). Segundo Tani et al. (2010), há modelos teóricos que possam subsidiar esta área de conhecimento. Destacam neste sentido, dois modelos teóricos, a saber: 1) Perspectiva dos Sistemas Motores (Teoria Motora) e 2) Perspectiva dos Sistemas de Ação (Teoria da Ação). No primeiro, a ênfase está no Sistema Nervoso Central (SNC) enquanto que, no segundo, o foco está nas informaçóes advindas do meio ambiente, mediante interação dinâmica dessa informação com o próprio corpo.

Independentemente do modelo, ambos perseguem o mesmo objetivo, ou seja, tentam explicar como os movimentos são apreendidos (Aprendizagem Motora), coordenados (Controle Motor) e organizados ao longo do tempo (Crescimento e Desenvolvimento Motor). A organização dos movimentos ao longo do tempo é um processo sequencial relacionado à idade cronológica, com interação entre a tarefa motora a ser executada, limites biológicos do indivíduo e o seu meio ambiente. Assim, há grande interesse entre os pesquisadores dessa área na infância, pois há intensas mudanças no processo de escolarização que irão depender destas interaçôes (CAETANO; SILVEIRA; GOBBI, 2006; ROSA NETO, et. al. 2010; COUTINHO; SOUZA; VALENTINI, 2016).

Muito embora haja conhecimento sobre o fato descrito anteriormente, no período escolar, ainda se encontra uma ênfase nas pesquisas no que diz respeito à aptidão física, portanto as pesquisas buscam compreender e explicar o movimento neuromuscular como atributo relacionado ao vigor físico e à saúde do indivíduo. Não que esta perspectiva não seja relevante, porém há necessidade e limites funcionais por parte das crianças (atraso no aprendizado, dificuldade motriz, falta de atenção, dentre outras) que irão implicar de forma positiva no processo ao longo do tempo ( $\mathrm{Na}$ organização vitalícia; quer sejam de natureza esportiva, recreativa ou da vida diária).

Assim, alguns autores (NETO, 2002; GALLAHUE; OZMUN, 2003; ROSA NETO et. al., 2010; MADASCHI; PAULA, 2011; COUTINHO; SOUZA; VALENTINI, 2016) têm procurado dar ênfase à aptidão motora, ou seja, à capacidade de realizar um movimento intencional (práxis motora), por meio da maturação e integração do sistema nervoso central (SNC). Portanto, Rosa Neto et al. (2010) propóe uma Escala de Desenvolvimento Motor (EDM). Refere-se à um instrumento composto por diversas baterias de testes a fim de avaliar o nível de desenvolvimento motor de crianças de 2 a 11 anos de idade. A ordem de sua aplicação é baseada nas idades cronológicas desses indivíduos, aumentando gradativamente o nível de dificuldade das tarefas juntamente com a idade (ARAÚJO, 2015).

Na literatura, é possível verificar várias propostas de avaliação no que diz respeito à aptidão motora (MADASCHI; PAULA, 2011; COUTINHO; SOUZA; VALENTINI, 2016), muito embora haja propostas que podem ser consideradas na literatura como "padrão ouro" há outras que podem ser verificadas com alta confiabilidade (NETO et. al., 2010) e que tem tido atenção nas pesquisas. E ainda, Neto et al. (2010, p. 423) alertam para o fato de que “[...] existem inúmeros testes e escalas para avaliação do desenvolvimento motor de uma criança, no entanto, quase nenhuma [...] engloba completamente todos os aspectos do desenvolvimento". 
O objetivo deste estudo foi analisar como está sendo aplicada a Escala de Desenvolvimento Motor (EDM), proposta por Neto (2002), em escolares brasileiros.

\section{Métodos}

Trata-se de um estudo qualitativo, do tipo descritivo, com delineamento do tipo revisão de literatura, sendo uma revisão sistemática realizada na base de dados: Google Acadêmico.

A pesquisa foi realizada na base de dados mencionada durante o período de quatro semanas, entre as datas de 15 de agosto à 15 de setembro de 2017. Nesse sentido, foram adotados como critérios para a inclusão dos textos: apenas estudos em português, com determinação cronológica compreendida entre 2013 e 2017, utilizando-se dos seguintes descritores: "Escala de Desenvolvimento Motor"; "Escola”; "Brasil".

As pesquisas foram realizadas na base de dados seguindo os critérios de seleção dos artigos, tendo como estratégia de busca o termo AND, que foi digitado entre as palavras no campo de busca disponível na base de dados. As pesquisas foram feitas com os descritores na língua portuguesa.

Desse modo, no período de busca realizada na base de dados Google Acadêmico, utilizando as três palavras juntas, foram encontrados 220 estudos. Foram analisados os resumos desses estudos, e então foram selecionados 46 estudos. Para que o artigo fosse selecionado este deveria conter em seu resumo as três palavras chave utilizadas no campo de busca.

Foram excluídos os estudos que não possuíam em seus resumos as três palavras chave utilizadas no campo de busca da base de dados, aqueles que não eram referentes à área de Educação Física e que estivessem em língua estrangeira. Foram excluídas as múltiplas versôes de um mesmo artigo, mantendo apenas uma única versão publicada.

Dessa forma, no final do período de busca, totalizou-se 14 estudos encontrados. Os resultados das buscas realizadas foram esquematizados e a mesma pode ser verificada na Figura 1, descrita a seguir:

Figura 1 - Processo de seleção dos estudos preparado para esta pesquisa.

Primeira etapa: Busca bibliográfica na base de dados Google Acadêmico utilizando-se dos seguintes descritores:

Escala de desenvolvimento motor, escola e Brasil. Totalizando 220 textos na busca inicial

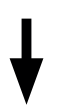

Segunda etapa: Leitura dos resumos dos textos. Após a leitura foram selecionados 46 estudos

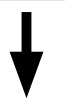

Terceira etapa: 32 textos excluídos por não serem referentes à área de Educação Física e possuir versóes repetidas

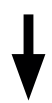

Quarta etapa: Total de 14 textos selecionados no final do período de busca

Fonte: autores 


\section{Resultados e discussão}

Após a revisão bibliográfica, pode-se observar que foram avaliadas cerca de 668 crianças, com idades variando entre 2 a 12 anos, pela Escala de Desenvolvimento Motor (EDM), proposta por Rosa Neto (2002), em 14 estudos. Destes manuscritos, apenas um estudo foi conduzido utilizando-se de uma amostra com crianças com deficiência, ou com algum transtorno de aprendizagem. Portanto, mais de $95 \%$ dos manuscritos foram conduzidos e avaliados em crianças que não apresentavam alguma anormalidade, quer seja ela física, mental, ou de outra natureza.

\begin{tabular}{|c|c|c|c|c|c|c|c|}
\hline Autores & Título do Artigo & Objetivo & Amostra & Característica & Resultado Final & Conclusáo & Estado \\
\hline $\begin{array}{c}\text { ALMEIDA , } \\
\text { LIMA } \\
2015\end{array}$ & $\begin{array}{c}\mathrm{O} \\
\text { desenvolvimento } \\
\text { motor em } \\
\text { escolares dos anos } \\
\text { iniciais do ensino } \\
\text { fundamental }\end{array}$ & $\begin{array}{c}\text { Avaliar o } \\
\text { desenvolvimento } \\
\text { motor, em } \\
\text { especifico os } \\
\text { aspectos da } \\
\text { motricidade fina } \\
\text { e equilíbrio. }\end{array}$ & $\begin{array}{c}38 \text { crianças de } \\
\text { ambos os sexos } \\
\text { com idade de } 7 \text { e } \\
\text { de } 10 \text { anos }\end{array}$ & REGULAR & $\begin{array}{c}\text { As crianças } \\
\text { mostraram } \\
\text { dificuldades na } \\
\text { realizaçấo do teste } \\
\text { da motricidade } \\
\text { fina quanto no } \\
\text { teste de equilíbrio } \\
\text { estático. }\end{array}$ & $\begin{array}{c}\text { As atividades } \\
\text { motoras săo } \\
\text { de suma } \\
\text { importância no } \\
\text { desenvolvimento } \\
\text { integral da } \\
\text { criança, pois } \\
\text { permite ter a } \\
\text { consciência } \\
\text { do seu eu e do } \\
\text { mundo exterior. }\end{array}$ & DF \\
\hline $\begin{array}{c}\text { ALOISE } \\
2017\end{array}$ & $\begin{array}{l}\text { Relaçáo entre o } \\
\text { perfil motor e a } \\
\text { leitura e escrita } \\
\text { em crianças } \\
\text { do ensino } \\
\text { fundamental }\end{array}$ & $\begin{array}{l}\text { Relacionar o } \\
\text { perfil motor } \\
\text { Com o nível de } \\
\text { compreensáo da } \\
\text { leitura e da escrita } \\
\text { de alunos do } \\
\text { terceiro ano do } \\
\text { ensino } \\
\text { Fundamental. }\end{array}$ & $\begin{array}{c}\text { Participaram } \\
38 \text { crianças ( } 21 \\
\text { meninas e } 17 \\
\text { meninos), com. } \\
\text { Idades } \\
\text { compreendidas } \\
\text { entre os } 8 \text { e os } 10 \\
\text { anos. }\end{array}$ & REGULAR & $\begin{array}{c}60,54 \% \text { das } \\
\text { crianças foram } \\
\text { classificadas com } \\
\text { o perfil Normal } \\
\text { Médio. } \\
\text { Relativamente } \\
\text { ao Perfil Motor, } \\
\text { os quocientes } \\
\text { relacionados com } \\
\text { a Motricidade } \\
\text { fina, } \\
\text { Motricidade } \\
\text { global, Equilíbrio } \\
\text { e Organizaçáo } \\
\text { Espacial, a } \\
\text { classificaçáo } \\
\text { foi de Normal } \\
\text { Médio. }\end{array}$ & $\begin{array}{c}\text { Foram registadas } \\
\text { associaçóes } \\
\text { significativas, } \\
\text { baixas e } \\
\text { moderadas, } \\
\text { entre o Perfil } \\
\text { Motor e o nível } \\
\text { de compreensão } \\
\text { da escrita e } \\
\text { da leitura, } \\
\text { sobressaindo, } \\
\text { nas correlaçóes, } \\
\text { a motricidade } \\
\text { fina, o equilíbrio, } \\
\text { a organizaçáo } \\
\text { espacial, e a } \\
\text { organizaçáo } \\
\text { temporal. }\end{array}$ & RO \\
\hline $\begin{array}{l}\text { ARANTES, } \\
\text { JUNIOR } \\
\text { Et. al } \\
2014\end{array}$ & $\begin{array}{c}\text { Influência } \\
\text { da atividade } \\
\text { psicomotora no } \\
\text { desenvolvimento } \\
\text { infantil }\end{array}$ & $\begin{array}{c}\text { Analisar a } \\
\text { influência } \\
\text { da atividade } \\
\text { psicomotora } \\
\text { orientada } \\
\text { (APO) sobre o } \\
\text { crescimento e } \\
\text { desenvolvimento } \\
\text { de escolares }\end{array}$ & $\begin{array}{l}60 \text { crianças de } \\
\text { ambos os sexos }\end{array}$ & REGULAR & $\begin{array}{l}\text { Resultados } \\
\text { homogêneos } \\
\text { na avaliação do } \\
\text { crescimento, } \\
\text { porém, a } \\
\text { classificação } \\
\text { nutricional } \\
\text { obtida pela } \\
\text { curva de } \\
\text { crescimento } \\
\text { IMC/idade } \\
\text { demonstrou } \\
\text { um número } \\
\text { considerável de } \\
\text { crianças obesas } \\
\text { em ambos os } \\
\text { grupos. }\end{array}$ & $\begin{array}{l}\text { as crianças } \\
\text { que receberam } \\
\text { atividade } \\
\text { psicomotora } \\
\text { orientada no } \\
\text { ambiente escolar } \\
\text { apresentaram } \\
\text { melhor } \\
\text { desempenho } \\
\text { psicomotor } \\
\text { comparado } \\
\text { às crianças que } \\
\text { não receberam } \\
\text { tais estímulos } \\
\text { orientados por } \\
\text { um profissional } \\
\text { especializado } \\
\text { da área do } \\
\text { movimento. }\end{array}$ & SP \\
\hline
\end{tabular}




\begin{tabular}{|c|c|c|c|c|c|c|c|}
\hline $\begin{array}{c}\text { ARAUJO } \\
2015\end{array}$ & $\begin{array}{c}\text { Comparação } \\
\text { dos aspectos } \\
\text { psicomotores } \\
\text { entre crianças que } \\
\text { Praticam } \\
\text { exercício físico e } \\
\text { crianças que não } \\
\text { praticam } \\
.\end{array}$ & $\begin{array}{c}\text { Analisar e } \\
\text { comparar a idade } \\
\text { cronológica e a } \\
\text { idade motora } \\
\text { entre } \\
\text { Crianças que } \\
\text { praticam } \\
\text { exercícios físicos } \\
\text { e crianças que } \\
\text { náo praticam } \\
\text { exercícios } \\
\text { Físicos }\end{array}$ & $\begin{array}{l}20 \text { crianças entre } \\
8 \text { e } 10 \text { anos. }\end{array}$ & REGULAR & $\begin{array}{c}60 \% \text { dos } \\
\text { indivíduos } \\
\text { praticam } \\
\text { exercícios } \\
\text { regularmente } \\
\text { e obtiveram os } \\
\text { maiores índices } \\
\text { de quociente } \\
\text { motor, estando } \\
\text { inseridos na } \\
\text { faixa entre } 100 \\
\text { e } 108.40 \% \\
\text { dos indivíduos } \\
\text { não praticam } \\
\text { exercícios } \\
\text { regularmente e } \\
\text { obtiveram índices } \\
\text { menores que } 100 \text {, } \\
\text { sendo inseridos } \\
\text { entre } 91 \text { e } 98 .\end{array}$ & $\begin{array}{l}\text { Os praticantes de } \\
\text { exercício físico } \\
\text { atingiram a média } \\
\text { de } 101,2 \text { no } \\
\text { Quociente motor e } \\
\text { foram classificados } \\
\text { no perfil motor } \\
\text { Normal médio } \\
\text { (90-109) enquanto } \\
\text { os năos praticantes } \\
\text { obtiveram uma } \\
\text { média de } 88,3 \text {, } \\
\text { tendo sido } \\
\text { classificados no } \\
\text { perfil motor. } \\
\text { Normal baixo (80- } \\
\text { 89), demonstrando } \\
\text { que a prática } \\
\text { dos exercícios } \\
\text { corrobora. }\end{array}$ & DF \\
\hline $\begin{array}{c}\text { CARVALHO, } \\
\text { CIASCA, } \\
\text { e RODRIGUES, } \\
2015\end{array}$ & $\begin{array}{c}\text { Há relaçăo entre } \\
\text { desenvolvimento } \\
\text { psicomotor e } \\
\text { dificuldade de } \\
\text { aprendizagem? } \\
\text { Estudo } \\
\text { comparativo de } \\
\text { crianças com } \\
\text { transtorno de } \\
\text { déficit de atençáo } \\
\text { e hiperatividade, } \\
\text { dificuldade } \\
\text { escolar e } \\
\text { transtorno de } \\
\text { aprendizagem. }\end{array}$ & $\begin{array}{c}\text { Avaliar o } \\
\text { desempenho } \\
\text { psicomotor de } \\
\text { crianças com } \\
\text { transtorno de } \\
\text { aprendizagem } \\
\text { (TA), dificuldade } \\
\text { escolar (DE) e } \\
\text { transtorno do } \\
\text { déficit de atenção } \\
\text { e hiperatividade } \\
\text { (TDAH). A } \\
\text { relaçáo entre } \\
\text { habilidades } \\
\text { psicomotoras nos } \\
\text { diferentes tipos de } \\
\text { problemas com a } \\
\text { aprendizagem. }\end{array}$ & $\begin{array}{l}\text { Foram avaliadas } \\
25 \text { crinças, de } \\
\text { ambos os gêneros, } \\
\text { com idade entre } \\
\text { sete e } 11 \text { anos de } \\
\text { idade. }\end{array}$ & DEFICIENTE & $\begin{array}{c}\text { Todas as } \\
\text { crianças tiveram } \\
\text { idade motora } \\
\text { inferior à idade } \\
\text { cronológica. }\end{array}$ & $\begin{array}{l}\text { Verificou-se que } \\
\text { o grupo com } \\
\text { TDAH teve pior } \\
\text { desempenho que } \\
\text { o DE e o TA, } \\
\text { porém diferença } \\
\text { estatisticamente } \\
\text { significativa só foi } \\
\text { identificada em } \\
\text { esquema corporal } \\
\text { (em comparaçáo } \\
\text { ao grupo DE) }\end{array}$ & SP \\
\hline $\begin{array}{c}\text { CUSTÓDIO, } \\
\text { FERRAZ } \\
2015\end{array}$ & $\begin{array}{c}\text { Aspectos } \\
\text { psicomotores e a } \\
\text { prática do judô } \\
\text { em escolares }\end{array}$ & $\begin{array}{c}\text { Descrever quais os } \\
\text { benefícios que o } \\
\text { desenvolvimento } \\
\text { psicomotor pode } \\
\text { trazer para a } \\
\text { vida da criança, } \\
\text { aplicar a escala de } \\
\text { desenvolvimento } \\
\text { motor em alunos } \\
\text { dos terceiro e } \\
\text { quarto anos } \\
\text { do ensino } \\
\text { fundamental e } \\
\text { apresentar os } \\
\text { resultados dessa } \\
\text { aplicaçấo. }\end{array}$ & $\begin{array}{l}30 \text { alunos do } 5^{\circ} \\
\text { ano do ensino } \\
\text { fundamental de } \\
\text { ambos os sexos. }\end{array}$ & REGULAR & $\begin{array}{l}\text { As crianças que } \\
\text { praticam judô } \\
\text { tiveram, no } \\
\text { geral, um melhor } \\
\text { desempenho } \\
\text { motor e possuem, } \\
\text { em sua maioria, } \\
\text { lateralidade } \\
\text { completa. }\end{array}$ & $\begin{array}{c}\text { O estímulo ao } \\
\text { desenvolvimento } \\
\text { da } \\
\text { psicomotricidade } \\
\text { na infância é de } \\
\text { suma importância } \\
\text { para o } \\
\text { desenvolvimento } \\
\text { motor da criança } \\
\text { e o judô pode } \\
\text { ser utilizado } \\
\text { como uma rica } \\
\text { ferramenta para } \\
\text { esse processo. }\end{array}$ & DF \\
\hline $\begin{array}{c}\text { DOMINGUES, } \\
\text { FURTADO E } \\
\text { RIBAS. } \\
2015\end{array}$ & $\begin{array}{c}\text { Desenvolvimento } \\
\text { neuropsicomotor } \\
\text { de escolares com } \\
\text { idade } \\
\text { Entre } 3 \text { e } 6 \\
\text { anos de uma } \\
\text { escola de curitiba- } \\
\text { pr }\end{array}$ & $\begin{array}{c}\text { Avaliar o } \\
\text { desenvolvimento } \\
\text { neuropsicomotor } \\
\text { de crianças com } \\
\text { idade entre } 3 \text { e } 6 \\
\text { anos. }\end{array}$ & $\begin{array}{l}19 \text { crianças com } \\
\text { idade entre } 3 \text { e } 6 \\
\text { anos, de ambos } \\
\text { os gêneros }\end{array}$ & REGULAR & $\begin{array}{c}\text { Ao analisar } \\
\text { os dados, foi } \\
\text { possível observar } \\
\text { que a amostra } \\
\text { apresentou } \\
\text { IMG acima } \\
\text { do esperado } \\
\text { com idade } \\
\text { positiva (IP) } \\
\text { de seis meses, e } \\
\text { desenvolvimento } \\
\text { motor classificado } \\
\text { como normal } \\
\text { alto. }\end{array}$ & $\begin{array}{l}\text { Os resultados } \\
\text { obtidos } \\
\text { demonstraram } \\
\text { que a amostra } \\
\text { estudada } \\
\text { apresenta } \\
\text { desenvolvimento } \\
\text { motor acima do } \\
\text { esperado para a } \\
\text { idade. }\end{array}$ & PR \\
\hline
\end{tabular}




\begin{tabular}{|c|c|c|c|c|c|c|c|}
\hline $\begin{array}{l}\text { FERREIRA, } \\
\text { SOUSA E } \\
\text { TAVARES } \\
2016\end{array}$ & $\begin{array}{l}\text { Aspectos motores } \\
\text { em crianças nas } \\
\text { séries iniciais } \\
\text { do ensino } \\
\text { fundamental }\end{array}$ & $\begin{array}{l}\text { Investigar se } \\
\text { crianças com } \\
\text { dificuldades de } \\
\text { aprendizagem } \\
\text { apresentam } \\
\text { algum }\end{array}$ & $\begin{array}{c}54 \text { escolares com } \\
\text { idades entre } 7 \text { e } \\
11 \text { anos. }\end{array}$ & REGULAR & $\begin{array}{l}\text { Quanto maior } \\
\text { a idade, melhor } \\
\text { os índices de } \\
\text { estatura, contudo, } \\
\text { pior os resultados } \\
\text { de motricidade } \\
\text { global e } \\
\text { equilíbrio. A } \\
\text { estatura também } \\
\text { foi uma das } \\
\text { variáveis que mais } \\
\text { influenciaram } \\
\text { nos resultados } \\
\text { gerais do estudo, } \\
\text { principalmente } \\
\text { as atividades } \\
\text { relacionadas ao } \\
\text { equilíbrio. }\end{array}$ & $\begin{array}{l}\text { Confirmou dados } \\
\text { de trabalhos } \\
\text { Recentes que } \\
\text { mostram a } \\
\text { importância da } \\
\text { estimulaçăo năo } \\
\text { só do aspecto } \\
\text { cognitivo, mas } \\
\text { também a parte } \\
\text { motora. }\end{array}$ & CE \\
\hline $\begin{array}{l}\text { OLIVEIRA } \\
2013\end{array}$ & $\begin{array}{c}\text { Análise do } \\
\text { nível de } \\
\text { desenvolvimento } \\
\text { motor em } \\
\text { crianças com } \\
\text { idade entre } 5 \text { a } 8 \\
\text { anos. }\end{array}$ & $\begin{array}{c}\text { Analisar } \\
\text { o nível de } \\
\text { desenvolvimento } \\
\text { motor em } \\
\text { crianças com } \\
\text { Idade entre } 5 \text { a } \\
8 \text { anos }\end{array}$ & $\begin{array}{c}30 \text { crianças com } \\
\text { idade entre } 5 \text { e } 8 \\
\text { anos (Educação } \\
\text { Infantil) }\end{array}$ & REGULAR & $\begin{array}{c}\text { Os resultados } \\
\text { obtidos reforçam } \\
\text { ainda mais a } \\
\text { ideia de que } \\
\text { o processo de } \\
\text { desenvolvimento } \\
\text { motor năo } \\
\text { acontece da } \\
\text { mesma forma e } \\
\text { nem ao mesmo } \\
\text { tempo para } \\
\text { todos. }\end{array}$ & $\begin{array}{c}\text { A maioria das } \\
\text { crianças que } \\
\text { foram avaliadas } \\
\text { apresenta } \\
\text { dificuldades } \\
\text { relacionadas ao } \\
\text { desenvolvimento } \\
\text { motor nas áreas } \\
\text { de motricidade } \\
\text { global e } \\
\text { Equilíbrio. }\end{array}$ & GO \\
\hline $\begin{array}{l}\text { SANTOS, } \\
\text { NETO, } \\
\text { PIMENTA. } \\
2013\end{array}$ & $\begin{array}{c}\text { Avaliaçâo das } \\
\text { habilidades } \\
\text { motoras } \\
\text { de crianças } \\
\text { participantes de } \\
\text { projetos sociais/ } \\
\text { esportivos }\end{array}$ & $\begin{array}{c}\text { Avaliar as } \\
\text { habilidades } \\
\text { motoras de } \\
\text { escolares } \\
\text { participantes dos } \\
\text { projetos sociais } \\
\text { educacionais, } \\
\text { projetos } \\
\text { esportivos e de } \\
\text { não participantes } \\
\text { em atividades } \\
\text { estruturadas } \\
\text { extraclasses. }\end{array}$ & $\begin{array}{l}136 \text { crianças de } \\
8 \text { a } 9 \text { anos, de } \\
\text { ambos os sexos, } \\
\text { de } 40 \text { escolas } \\
\text { públicas. }\end{array}$ & REGULAR & $\begin{array}{c}\text { Padróes de } \\
\text { desenvolvimento } \\
\text { motores mais } \\
\text { elevados } \\
\text { em crianças } \\
\text { participantes de } \\
\text { projetos com } \\
\text { caráter esportivo } \\
\text { e padróes } \\
\text { expressivos } \\
\text { de baixa } \\
\text { coordenação } \\
\text { nas crianças que } \\
\text { não participam } \\
\text { de projetos } \\
\text { ou atividades } \\
\text { estruturadas fora } \\
\text { da escola. }\end{array}$ & $\begin{array}{l}\text { a prática de } \\
\text { atividades esportivas, } \\
\text { realizadas através dos } \\
\text { projetos esportivos, } \\
\text { demonstrou } \\
\text { ser um fator } \\
\text { significativamente } \\
\text { favorável à } \\
\text { motricidade de seus } \\
\text { participantes. }\end{array}$ & SC \\
\hline $\begin{array}{c}\text { SILVA, SOUSA } \\
\text { E PAULINO } \\
2017\end{array}$ & $\begin{array}{c}\text { Analise do } \\
\text { desenvolvimento } \\
\text { motor em } \\
\text { escolares de } 4 \text { a } \\
5 \text { anos } \\
\text { Das escolas } \\
\text { privadas do } \\
\text { município de } \\
\text { Santana }\end{array}$ & $\begin{array}{c}\text { Analisar o } \\
\text { desenvolvimento } \\
\text { motor das } \\
\text { crianças de } 4 \\
\text { a } 5 \text { anos da } \\
\text { rede privada } \\
\text { de Santana, } \\
\text { averiguar em } \\
\text { que nível de } \\
\text { desenvolvimento } \\
\text { motor as crianças } \\
\text { de } 4 \text { a } 5 \text { anos se } \\
\text { encontram. }\end{array}$ & $\begin{array}{l}20 \text { alunos de } 4 \text { a } \\
5 \text { anos. }\end{array}$ & REGULAR & $\begin{array}{c}\text { Os alunos } \\
\text { apresentaram o } \\
\text { desenvolvimento } \\
\text { dentro da } \\
\text { normalidade. } \\
\text { Deseja-se que os } \\
\text { profissionais da } \\
\text { área planejem } \\
\text { suas aulas com } \\
\text { mais qualidade, } \\
\text { buscando sempre } \\
\text { a progressão } \\
\text { dos seus alunos, } \\
\text { respeitando a } \\
\text { individualidade e } \\
\text { ritmo de cada. }\end{array}$ & $\begin{array}{l}\text { Apesar da maioria } \\
\text { dos avaliados } \\
\text { estarem na média } \\
\text { esperada para } \\
\text { a sua Idade foi } \\
\text { identificada em } \\
\text { ambas às escolas } \\
\text { percentuais } \\
\text { que estavam } \\
\text { abaixo da média, } \\
\text { mostrando } \\
\text { assim que o } \\
\text { desenvolvimento } \\
\text { dessas crianças } \\
\text { năo está } \\
\text { conforme } \\
\text { a sua idade } \\
\text { cronológica. }\end{array}$ & $\mathrm{AP}$ \\
\hline
\end{tabular}




\begin{tabular}{|c|c|c|c|c|c|c|c|}
\hline $\begin{array}{l}\text { VALA, } \\
\text { BARRETO } \\
2016\end{array}$ & $\begin{array}{c}\text { O } \\
\text { desenvolvimento } \\
\text { motor de crianças } \\
\text { obesas durante as } \\
\text { aulas de educaçáo } \\
\text { física escolar }\end{array}$ & $\begin{array}{c}\text { Analisar o } \\
\text { desenvolvimento } \\
\text { motor de } \\
\text { crianças obesas } \\
\text { regularmente } \\
\text { matriculadas } \\
\text { no Ensino } \\
\text { Fundamental I. }\end{array}$ & $\begin{array}{c}83 \text { alunos com } \\
\text { idade entre } 6 \text { e } 12 \\
\text { anos. }\end{array}$ & REGULAR & $\begin{array}{c}\text { O aumento } \\
\text { da quantidade } \\
\text { de aulas de } \\
\text { Educação Física } \\
\text { nas escolas } \\
\text { pode trazer, } \\
\text { em nível de } \\
\text { desenvolvimento } \\
\text { motor. Os alunos } \\
\text { teriam um tempo } \\
\text { maior em contato } \\
\text { com a prática } \\
\text { física }\end{array}$ & $\begin{array}{l}\text { O atraso motor } \\
\text { pode ser causado } \\
\text { pela inatividade } \\
\text { ligada ao estado } \\
\text { de obesidade, } \\
\text { causando } \\
\text { dificuldade } \\
\text { para realizaçăo } \\
\text { de atividades, } \\
\text { vergonha da } \\
\text { exposiçáo de } \\
\text { sua aparência } \\
\text { corporal. O } \\
\text { cuidado para } \\
\text { náo se expor } \\
\text { faz com que o } \\
\text { obeso escolha } \\
\text { as atividades } \\
\text { com baixo gasto } \\
\text { calórico }\end{array}$ & SP \\
\hline $\begin{array}{c}\text { VIEIRA, } \\
\text { OLIVEIRA e }\end{array}$ & $\begin{array}{l}\text { Perfil motor } \\
\text { de escolares da } \\
\text { rede pública do } \\
\text { município de } \\
\text { chapecó. }\end{array}$ & $\begin{array}{c}\text { Nesta pesquisa se } \\
\text { objetivou verificar } \\
\text { o perfil motor } \\
\text { dos escolares } \\
\text { do Ensino } \\
\text { Fundamental } \\
\text { I da Escola } \\
\text { Estadual Básica } \\
\text { Druziana Sartori } \\
\text { da rede pública } \\
\text { do Município de } \\
\text { Chapecó, SC. }\end{array}$ & $\begin{array}{l}\text { Composta por } \\
91 \text { escolares de } \\
\text { ambos os sexos }\end{array}$ & REGULAR & $\begin{array}{l}\text { Somente } \\
\text { no esquema } \\
\text { corporal, } \\
\text { organizaçăo } \\
\text { espacial e } \\
\text { estrutura } \\
\text { temporal } \\
\text { os escolares } \\
\text { apresentaram } \\
\text { uma idade } \\
\text { motora abaixo da } \\
\text { média de idade } \\
\text { cronológica. }\end{array}$ & $\begin{array}{l}\text { Os escolares, } \\
\text { em geral, não } \\
\text { apresentam um } \\
\text { déficit motor, } \\
\text { por mais que, } \\
\text { em algumas } \\
\text { habilidades } \\
\text { motoras eles } \\
\text { tenham ficado } \\
\text { com uma idade } \\
\text { motora abaixo da } \\
\text { esperada. }\end{array}$ & SC \\
\hline $\begin{array}{l}\text { ZAGO, } \\
\text { ZOLETT } \\
2016\end{array}$ & $\begin{array}{c}\text { Relação idade } \\
\text { cronológica e } \\
\text { idade motora dos } \\
\text { alunos do ensino } \\
\text { fundamental i } \\
\text { de duas escolas } \\
\text { no municipio de } \\
\text { fraiburgo, sc }\end{array}$ & $\begin{array}{c}\text { Identificar o } \\
\text { desempenho } \\
\text { motor de crianças } \\
\text { de } 10 \text { anos de } \\
\text { duas escolas } \\
\text { públicas da } \\
\text { rede municipal } \\
\text { de ensino de } \\
\text { Friburgo-Sc } \\
\text { sendo uma escola } \\
\text { da zona urbana } \\
\text { e uma da zona } \\
\text { rural. }\end{array}$ & $\begin{array}{l}24 \text { crianças, com } \\
\text { idade cronológica } \\
\text { de } 10 \text { anos. }\end{array}$ & REGULAR & $\begin{array}{c}\text { Na avaliação } \\
\text { do equilíbrio } \\
\text { 7\% das crianças } \\
\text { apresentaram a } \\
\text { idade motora } \\
\text { abaixo da sua } \\
\text { idade } \\
\text { Cronológica } \\
\text { e na escola da } \\
\text { zona rural 38\% } \\
\text { dos alunos } \\
\text { apresentaram } \\
\text { dificuldades no } \\
\text { seu equilíbrio. }\end{array}$ & $\begin{array}{l}\text { A maioria das } \\
\text { crianças avaliadas } \\
\text { apresenta algum } \\
\text { atraso motor, } \\
\text { ou seja, não } \\
\text { conseguiram } \\
\text { realizar o teste } \\
\text { motor e indicado } \\
\text { para sua idade } \\
\text { cronológica, e } \\
\text { sim para idades } \\
\text { inferiores, } \\
\text { apresentando } \\
\text { idade motora } \\
\text { aquém da idade } \\
\text { cronológica. }\end{array}$ & SC \\
\hline
\end{tabular}

As pesquisas apresentadas nesta revisão bibliográfica mostraram que a maioria delas se concentra no Estado de Santa Catarina, em Sáo Paulo e Distrito Federal. Muito embora houvessem maiores concentrações nestes estados, observam-se pesquisas sendo realizadas em Mato Grosso; Rio Grande do Sul; Amazonas; Amapá; Ceará; Rondônia; Goiás e Paraná. Podemos observar que a maior parte desses estudos ocorreram na rede pública de ensino.

O objetivo deste estudo foi verificar como está sendo aplicada a Escala de Desenvolvimento Motor (EDM), proposta por Neto (2002), em escolares brasileiros. A partir de uma revisão sistemática foram abordados os principais resultados encontrados nesses estudos e foi possível realizar comparaçôes entre as informaçóes encontradas na literatura. Dezoito estudos atenderam os critérios de inclusão desta revisão. Todos os estudos trabalharam com meninos e meninas, a faixa etária 
variou de 2 a 12 anos e todas as intervençôes foram realizadas na escola (escolas públicas em sua maioria). Foram avaliadas cerca de 668 crianças.

Por meio da revisão sistemática foi possível perceber a importância de priorizar a prática de uma modalidade esportiva no âmbito escolar, uma vez que os estudos que apresentaram os melhores resultados estavam associados a projetos de atividades extracurriculares. É possível perceber que o esporte tem grande impacto no que diz respeito ao desenvolvimento motor nos alunos, possibilitando a criação de estratégias de intervenção ou programas de treinamento sistematizados no ambiente escolar.

Com isso, foi possível articular argumentos com relação à prática esportiva sistematizada no ambiente escolar e realizar comparaçóes entre os estudos que abordam ou não essa perspectiva.

No estudo de Almeida e Lima (2015) foram escolhidos dois elementos básicos da motricidade: a motricidade fina e o equilíbrio. Neste estudo observou-se que nenhum dos escolares apresentou desenvolvimento motor igual às suas idades cronológica. O teste aplicado para identificar o desenvolvimento da motricidade fina apontou um comprometimento da coordenação motora, pois os alunos sentiram dificuldade na execução de movimentos circulares, mostrando uma dificuldade na associação descrita como percepção cognitiva e motora.

O teste para verificar o equilíbrio estático apresentou resultados comprometedores, uma vez que tanto as crianças de sete como as de dez anos de idade não foram capazes de ser manter na posição estática por mais de 10 segundos, ressaltando que o equilíbrio poderia ser um aspecto que necessita ser mais trabalhado nas aulas de educação física (ALMEIDA, LIMA, 2015).

No estudo de Custódio e Ferraz (2015), é abordada uma modalidade esportiva específica: o judô. Os autores apontaram que esta modalidade esportiva, quando trabalhado de forma lúdica, poderia favorecer o desenvolvimento e a aprendizagem motora. Descrevem ainda que, a prática de judô beneficia o desenvolvimento de habilidades motoras básicas e específicas da criança, e que poderiam auxiliar na formação de um amplo repertório motor.

Se compararmos o estudo de Almeida e Lima (2015) em relação ao estudo de Custódio e Ferraz (2015), ambos realizados no âmbito escolar, percebemos a importância de priorizar a prática de uma modalidade esportiva, e como esta pode estar relacionada ao desenvolvimento motor eficaz dos alunos. A capacidade de equilíbrio estático foi observada em ambos os estudos, porém percebemos que no estudo de Almeida e Lima (2015) as crianças apresentaram dificuldade na percepção de equilíbrio corporal, ficando abaixo de suas idades cronológicas enquanto que no estudo de Custódio e Ferraz (2015), 67\% das crianças que praticam judô ficaram acima da idade cronológica. Fato este que poderia corroborar e ser explicado pelas atividades extracurriculares.

Outro aspecto avaliado na Escala foi a Motricidade fina em crianças de 10 anos de idade. No estudo de Almeida e Lima (2015) a motricidade fina dos escolares apresentou-se comprometida, pois sentiram dificuldade na execução dos movimentos, na percepção cognitiva e no aspecto motor. Entretanto, no estudo de Custódio e Ferraz (2015), não ficaram claras estas evidências, portanto não indicando que poderia haver benefícios desta atividade quando comparado o estudo de Almeida e Lima (2015).

Araújo (2015) analisou cerca de 20 crianças com idade compreendida entre 7 e 10 anos de uma escola situada em Brasília (DF), dentre as quais, 10 dessas crianças eram praticantes de atividades motoras como handball, basquete, natação, equitação, badminton, futebol e tênis, enquanto que, as 
outras 10 crianças não praticavam nenhuma modalidade esportiva (grupo controle). O objetivo do estudo foi analisar e comparar tanto a idade cronológica como a idade motora entre as crianças praticantes e não praticantes destas atividades motoras.

O grupo que praticava atividade motora atingiu, em média, um Quociente Motor mais elevado quando comparado ao grupo que não praticava atividade; bem como foram classificados com um perfil motor Normal Baixo. Em outras palavras, a prática destas atividades corroborou significativamente para o desenvolvimento dos aspectos motores. Estes dados são similares aos resultados encontrados no estudo de Santos, Neto e Pimenta (2013).

Entre os três estudos provenientes do Distrito Federal, podemos observar que o estudo de Araújo (2015) não abordou os aspectos motores de equilíbrio e motricidade fina enquanto que nos estudos de Almeida e Lima (2015) e Custódio e Ferraz (2015) foram analisados esses aspectos. Araújo (2015) deu maior ênfase na análise da Idade Motora Global (IMG) e do Quociente Motor, classificando os resultados de acordo com o Manual de Avaliação Motora proposta por Rosa Neto (2002). Realizamos esta comparação entre estes três estudos por serem publicações de uma mesma regiáo e no mesmo período cronológico, evidenciando que, apesar de possuírem grandes semelhanças, analisaram elementos distintos do desenvolvimento motor.

Estes três estudos realizados no Distrito Federal coincidem no que diz respeito à prática de atividades motoras poderiam beneficiar no desenvolvimento motor das crianças, pois

[...] a aquisição das habilidades motoras está relacionada ao desenvolvimento da percepção corporal, espacial e temporal, onde estas habilidades constituem componentes básicos de domínio, tanto para a aprendizagem motriz como para as atividades onde haja formaçáo escolar, ou seja, quanto antes trabalharmos os aspectos motores das crianças, melhores serão os aportes em todas as áreas (cognitiva, sócio afetiva e psicomotora) (ARAÚJO, 2015, p. 15).

Embora os três estudos fossem de uma mesma região e realizados no mesmo ano em escolares com idade compreendida entre 7 e 10 anos, foi possível observar que o desenvolvimento motor, bem como a aquisição de padróes e de seus aspectos motores variaram entre os participantes, porém corroborando com os dados da literatura.

Entende-se que o desenvolvimento motor nem sempre segue um padrão, podendo haver comprometimento de algum componente avaliado, isto é, variando entre os indivíduos. Vários autores consideram as alteraçóes no desenvolvimento motor dentro do padrão de normalidade, pois cada indivíduo possui diferentes ritmos de desenvolvimento, interferindo nos aspectos afetivo, social e cognitivo (ALMEIDA; LIMA, 2015, p. 13).

Oliveira (2013) define que a infância é uma fase muito importante para o desenvolvimento motor dos indivíduos, pois é nesta fase que as crianças buscam o novo por meio da exploração do mundo 
a sua volta. Esta exploraçáo ocorre, principalmente, pela manipulação de objetos e interação entre o indivíduo e o seu meio social. $\mathrm{O}$ autor observou que a maioria das crianças, de 5 a 8 anos, apresentou nível de Desenvolvimento Motor abaixo do esperado (OLIVEIRA, 2013). Durante este estudo foi possível observar por meio dos resultados obtidos que: "as capacidades perceptivo-motoras desenvolvem-se rapidamente, mas com frequência há confusão em relação à sensação do corpo, ao senso de direção, de tempo e de espaço (GALLAHUE; OZMUN 2013, p.195 apud OLIVEIRA, 2013, p.17).

Sendo assim:

[...] este dado nos remete a importância de se realizar avaliaçóes motoras em crianças, uma vez que, identificadas as alteraçóes das habilidades motoras que podem interferir na aprendizagem escolar ou conduta geral da criança, pode-se realizar uma intervenção nesse sentido já que, posteriormente, na fase adulta, o indivíduo precisará destas habilidades para a realização de tarefas básicas (OLIVEIRA, 2013, p.28).

A Educação Física assume um papel importante no desenvolvimento das habilidades motoras básicas, pois é a partir das vivências e dos estímulos gerados pelo meio que as crianças aprendem, ou seja, são instigadas à experimentação e as novas descobertas. Percebe-se que por meio da Educação Física, pode-se abrir um leque de possibilidades que podem ser propostas às crianças e que, em certa medida, poderá afetar a sua motricidade, porém de forma natural e prazerosa (OLIVEIRA, 2013).

Diferentemente dos estudos de Custódio e Ferraz (2015) e Araújo (2015), o estudo de Oliveira (2013) não se utilizou da aplicação de modalidades esportivas nos indivíduos que pertenciam a amostra, assemelhando-se ao estudo de Almeida e Lima (2015) ao excluir os alunos que praticassem qualquer tipo de atividade motora sistematizada.

Com relaçáo ao desenvolvimento motor dos escolares apresentados na pesquisa de Custódio e Ferraz (2015), bem como de Araújo (2015) parecem superar o que foi observado por Almeida e Lima (2015) e Oliveira (2013). Com isso, parece ser possível analisar que os escolares que praticam alguma modalidade esportiva parecem apresentar melhores resultados quanto aos seus aspectos motores durante o seu desenvolvimento (ARAÚJO, 2015).

Em comparação, vemos que tanto no estudo de Oliveira (2013) como no de Almeida e Lima (2015), as crianças avaliadas apresentam dificuldades relacionadas ao desenvolvimento motor na área de equilíbrio, pois

[...] este fato é extremamente preocupante visto que, a infância é a fase da experimentação [...] e se o indivíduo não recebe os estímulos para o desenvolvimento destas habilidades nessa fase, dificilmente isso acontecerá em fases posteriores (OLIVEIRA, 2013, p.30).

No estudo de Ferreira, Souza e Tavares (2016) foram possíveis observar que há diferenças nos desempenhos quando observados os testes motores; quanto ao gênero; estado nutricional (avaliado pelo Índice de Massa Corpórea - IMC), bem como em função da idade, portanto corroborando 
com os estudos de Oliveira (2013) e Almeida e Lima (2015) no que diz respeito ao processo do desenvolvimento motor como um fator individual, variando de pessoa para pessoa em ritmos diferentes, portanto possuindo o tempo próprio.

Ao observarmos na literatura os estudos conduzidos no estado de Sáo Paulo, em sua maioria, o objetivo foi avaliar o desempenho motor com crianças com diagnóstico de Dificuldade Escolar; Transtorno do Déficit de Atenção e Hiperatividade (TDAH); Transtorno de Atenção e Atividade Psicomotora Orientada (APO). Estes estudos foram apresentados por Carvalho, Ciasca e Rodrigues (2015); Arantes, Junior et al. (2014) e Vala, Barreto (2016). O que ambos os estudos apontam é a relevância das atividades motoras nestes diagnósticos, pois os estímulos podem impactar de forma positiva na vida destas crianças.

Nos resultados obtidos por Aloise (2017), vemos que a aplicação da Escala de Desenvolvimento Motor (EDM), Escala de Avaliação da Escrita (EAVE), Escala de Reconhecimento das Palavras (EREP) - instrumento utilizado para medir o nível de escrita e compreensáo da leitura - e o Teste de Cloze (Avaliação da Compreensão em Leitura), nos permitiu averiguar que as capacidades motoras trabalhadas de modo inadequado com as crianças podem gerar sequelas que levam a confusóes de espaços, dificuldade de coordenação, lentidão de movimentos, e dificuldade nos sentidos de direção. Isso pode ser explicado pelo fato de que as capacidades motoras necessitam ser trabalhadas de forma conjunta para o funcionamento ocorrer de forma plena. Aloise (2017, p. 35) afirma ainda que, alunos organizados no tempo, mas não no espaço, podem vir a tornarem-se leitores pobres, evidenciando reduzida velocidade de leitura, pois a

[...] escrita é o resultado de uma organização de movimentos, pelo que um desenvolvimento psicomotor comprometido pode levar a problemas na direção gráfica, na distinção de letras, na ordenação de sílabas, bem como no pensamento lógico e na análise gramatical.

Silva, Sousa e Paulino (2017) realizaram estudo de campo afim de averiguar, identificar e analisar como está o Desenvolvimento Motor de crianças entre 4 a 5 anos devidamente matriculados na rede privada da cidade de Santana, debatendo a importância do profissional de Educação Física para a aprendizagem e aperfeiçoamento das habilidades motoras. Como resultado, as crianças apresentaram média aceitável para sua idade, porém foi identificado que nas duas escolas tiveram percentuais abaixo da média, mostrando que as crianças não estão sendo desenvolvidas conforme a sua Idade Cronológica.

A partir disso, parece ficar claro que a presença do professor de Educação Física, nos primeiros anos escolares, utilizando-se de atividades psicomotoras, poderá auxiliar no desenvolvimento físico, cognitivo, afetivo e social, portanto fornecendo subsídios para que o mesmo tenha seu desenvolvimento motor compatível com a sua Idade Cronológica (SILVA; SOUSA; PAULINO, 2017).

Parece que

[...] vários autores consideram as alteraçôes no desenvolvimento motor dentro do padrão de normalidade, pois cada indivíduo possui diferentes ritmos de desenvolvimento, interferindo nos aspectos afetivo, social e cognitivo (ALMEIDA; LIMA, 2015, p.13). 
No estudo de Vieira, Oliveira e Werkhauser (2015) foram possíveis avaliar a idade cronológica em habilidades motoras e esquemas corporais, noção espacial e estrutura corporal dos alunos de 6 a 10 anos. Os resultados encontrados para essa pesquisa foram de normal médio, porém as habilidades motoras e o esquema corporal, a organização espacial, bem como a estrutura temporal foram identificados abaixo da média em relação à idade cronológica, assim como nos estudos de Almeida e Lima (2015) e Oliveira (2013).

Domingues, Furtado e Ribas (2015) mostraram que os resultados de lateralidade foram classificados com nível motor alto, exceto a motricidade fina que foi abaixo do esperado para sua idade cronológica. Sendo assim, o desenvolvimento das crianças foi acima da média esperada, porém os autores não deixam claro o porquê deste fenômeno ter ocorrido.

Zago e Zolette (2016) verificaram o desempenho motor de crianças de 10 anos de duas escolas públicas da rede municipal de ensino de Fraiburgo-SC, em ambientes diferentes, ou seja, na parte urbana e rural. Identificaram que, ambas as crianças ficaram abaixo da média. Entretanto, os autores não esclarecem o que poderia explicar este fato.

\section{Conclusão}

Levando em consideração o nosso objetivo que foi analisar como está sendo aplicada a Escala de Desenvolvimento Motor (EDM), proposta por Neto (2002), em escolares brasileiros foi possível concluir que:

- Parece ser necessário implementar programas de atividades motoras que envolvam modalidades esportivas extracurriculares ou integradas ao Projeto Político Pedagógico da escola, favorecendo assim, o desenvolvimento e a aprendizagem de diferentes habilidades motoras em escolares matriculados no ensino fundamental;

- A motricidade fina é um aspecto motor que deve ser amplamente trabalhado nas aulas de Educação Física, pois se apresentou comprometido na maioria dos estudos;

- Em grande parte dos estudos foi possível observar que a maioria das crianças apresentou um nível de desenvolvimento motor abaixo de sua Idade Cronológica, sendo assim as aulas de Educação Física poderiam sanar, em certa medida, esta necessidade;

- Para a maioria dos autores parece que o processo de desenvolvimento motor é um fenômeno individual, por mais que a literatura aponte que há um padrão de aquisição de aspectos motores;

- A utilização da escala de desenvolvimento motor parece ser um instrumento de avaliação indispensável ao Profissional de Educação Física, pois o professor poderá estruturar suas aulas a fim de melhorar o desempenho negativo apresentado nos testes;

- A Escala de Desenvolvimento Motor (EDM) está sendo aplicada de forma fragmentada, não englobando completamente todos os aspectos motores dos escolares. Provavelmente, pelo curto período de tempo disponível para coleta de dados e aplicação da bateria de testes no âmbito escolar.

\section{Referências}

ALMEIDA, A. J. M. de.; LIMA, L. dos S. O desenvolvimento motor em escolares dos anos iniciais do ensino fundamental. 31 .2015 f. TCC (Graduação) - Curso de Licenciatura em Educação Física, Centro Universitário de Brasilia- Uniceub, Brasilia, 2015. Disponível em: <http://repositorio.uniceub.br/bitstream/235/7561/1/21364594.pdf>. Acesso em: 11 set. 2017. 
ALOISE, M. H. Relação entre o perfil motor e a leitura e escrita em crianças do ensino fundamental. 2017. 71 f. Dissertação (Mestrado) - Curso de Educação Física, Universidade de Trás-osmontes e Alto Douro, Vila Real, 2017. Disponível em: <http://repositorio.utad.pt/handle/10348/7964>. Acesso em: 15 set. 2017.

ARANTES, M. S. et al. Influência da atividade psicomotora no desenvolvimento infantil. Colloquium Vitae, Presidente Prudente, v. 6, n. 2, p.71-78, Ago. 2014. Disponível em: <file:///C:/Users/claudiodaluzz/ Downloads/1197-5166-2-PB.pdf>. Acesso em: 23 ago. 2017.

ARAÚJO, L. F. de. Comparaçáo dos aspectos psicomotores entre crianças que praticam exercício físico e crianças que náo praticam. 26 .2015 f. TCC (Graduação) - Curso de Bacharelado em Educação Física, Centro Universitário de Brasília - Uniceub Faculdade de Ciências da Educação e Saúde -faces, Brasilia, 2015. Disponível em: <http://repositorio.uniceub.br/bitstream/235/7524/1/21245650.pdf>. Acesso em: 06 set. 2017.

CAETANO, M. J. D.; SILVEIRA, C. R. A. e GOBBI, L. T. B. Desenvolvimento motor de pré-escolares no intervalo de 13 meses. Revista Brasileira de Cineantropometria \& Desempenho Humano. v.7, n.2, p. $05-13,2006$.

CARVALHO, M. C.; CIASCA, S. M.; RODRIGUES, S. das D. Há relação entre desenvolvimento psicomotor e dificuldade de aprendizagem?: Estudo comparativo de crianças com transtorno de déficit de atenção e hiperatividade, dificuldade escolar e transtorno de aprendizagem. Revista Psicopedagógica, São Paulo, v. 32, n. 99, p. 293-301, 2015. Disponível em: <http://pepsic.bvsalud.org/scielo.php?script=sci_arttext\&pid=S0103-84862015000300003\&lng=pt\&nrm=iso >. Acesso em: 13 set. 2017.

COUTINHO, M. T.; SOUZA, M. S. e VALENTINI, N. C. Crianças com desordem coordenativa desenvolvimental percebem-se menos competente e evidenciam autoconceito fragilizado. Revista Brasileira de Ciências e Movimento. v.24, n.4, p. 5-15, 2016.

CUSTÓDIO, R. de A.; FERRAZ, M. A. Aspectos psicomotores e a prática do judô em escolares.2015. 38 f. TCC (Graduação) - Curso de Licenciatura em Educação Física, Faculdade de Ciências da Educação e Saúde Centro Universitário de Brasília - Uniceub., Brasilia, 2015. Disponível em: <http://repositorio.uniceub.br/bitstream/235/7554/1/21349680.pdf>. Acesso em: 13 set. 2017.

DOMINGUES, B. T.; FURTADO, R. B.; RIBAS, D. I. R. Desenvolvimento neuropsicomotor de escolares com idade entre 3 e 6 anos de uma escola de Curitiba-PR., Anais do EVINCI - UniBrasil, Curitiba, out. 2015. Disponível em: <http://portaldeperiodicos.unibrasil.com.br/index.php/anaisevinci/article/ view/834>. Acesso em: 11 Set. 2017.

FERREIRA, M. P.; SOUSA, G. das C. D.; TAVARES, E. D. Aspectos motores em crianças nas séries iniciais do ensino fundamental. 4 .2016 f. TCC (Graduação) - Curso de Educação Física, Centro Universitário Católica de Quixadá, Quixeramobim, 2016. Disponível em: <http://publicacoesacademicas.fcrs.edu.br/index.php/eedic/article/ view/616/863>. Acesso em: 12 set. 2017.

GALLAHUE, D. L.; OZMUN, J. C. Compreendendo o desenvolvimento motor: bebês, crianças, adolescentes e adultos. São Paulo: Phorte, 2003.

MADASCHI, V.; PAULA, C. S. Medidas de avaliação do desenvolvimento infantil: uma revisão da literatura nos últimos cinco anos. Cadernos de Pós-Graduaçáo em Distúrbios do Desenvolvimento. v. 11, n.1, p.52-6, 2011. 
OLIVEIRA, A. R. de. Análise do nível de desenvolvimento motor em crianças com idade entre 5 a 8 anos. 2013. 38 f. TCC (Graduação) - Curso de Educação Física, Universidade Federal de Goiás Faculdade de Educação Física, Formosa, 2013. Disponível em:<http://repositorio.bc.ufg.br/bitstream/ri/4533/5/ TCCG\%20\%20Biblioteconomia\%20-\%20Andreia\%20Rodrigues\%20de\%20Oliveira.pdf>. Acesso em: 18 Ago. 2017.

ROSA NETO, F. et al. Importância da avaliação motora em escolares: análise da confiabilidade da Escala de Desenvolvimento Motor. Revista Brasileira de Cineantropometria \& Desempenho Motor. v.12, n.6, p.422-427, 2010.

ROSA NETO, F. Manual de avaliaçáo motora. Porto Alegre: Artmed, 2002.

SANTOS, A. P. M. dos; ROSA NETO, F.; PIMENTA, R. de A. Avaliação das habilidades motoras de crianças participantes de projetos sociais/esportivos. Revista Motriz., Vila Real , v. 9, n. 2, p. 61-51, Abr. 2013. Disponível em <http://www.scielo.mec.pt/scielo.php?script=sci_arttext\&pid=S107-1646X20130002 00006\&lng=pt\&nrm=iso $>$. Acesso em 13 Set. 2017. http://dx.doi.org/10.6063/motricidade.2667.(2)9.

SILVA, B. C.; SOUSA, J. M.; PAULINO, J. A. da S. Análise do Desenvolvimento Motor em escolares de 4 a 5 anos das escolas privadas do município de Santana. Mostra Científica dos acadêmicos do $5^{\circ}$ semestre do curso de Licenciatura em Educaçáo Física/CEAP. Macapá/AP, 2017. Disponível em: <http:// escolar.universoef.com.br/container/gerenciador_de_arquivos/arquivos/371/desenv-motor-escolares-4-5anos-escolas-privadas-santana.pdf $>$. Acesso em: 11 set. 2017.

TANI, G. et al. Pesquisa na área de comportamento motor: modelos teóricos, métodos de investigação, instrumentos de análise, desafios, tendências e perspectivas. Revista de Educaçáo Física de Maringa (UEM). v.21, n.3, p. 329-380, 2010.

VALA, T. M.; BARRETO, S. M. G. O Desenvolvimento motor de crianças obesas durante as aulas de Educação Física escolar. Revista Científica-Cultural, [S.1.], v. 1, n. 01, p. 18, nov. 2016. ISSN 25260766. Disponível em: <http://cientifica.facem.com.br/index.php/revista/article/view/24>. Acesso em: 03 set. 2017.

VIEIRA, M. P.; OLIVEIRA, S. R.; WERHAUSER, S. Perfil motor de escolares da rede pública do município de Chapecó. Unoesc \& Ciência, Joaçaba, v. 1, p.79-86, Set. 2015. Disponível em: <http://editora. unoesc.edu.br/index.php/siepe/article/view/7852 >. Acesso em: 20 ago. 2017.

ZAGO, E. A.; ZOLETT, S. Relação Idade Cronológica e Idade Motora dos alunos do ensino fundamental I de duas escolas do município de Fraiburgo, SC. Seminário de Iniciaçáo Científica, Seminário Integrado de Ensino, Pesquisa e Extensáo e Mostra Universitária, [S.l.], ago. 2016. ISSN 2237-6593. Disponível em: <http://editora.unoesc.edu.br/index.php/siepe/article/view/11196/5774>. Acesso em: 03 set. 2017.

SCHŐN, D. A. Formar Professores como Profissionais Reflexivos. In: NÓVOA, A (Coordenador). Os Professores e a sua Formaçáo. Lisboa: Publicações Dom Quixote, 1997, p. 77-92.

SMOLE, K. S.; DINIZ, M. I. (Org.). Ler, escrever e resolver problemas: habilidades básicas para aprender matemática. Porto Alegre: Artmed, 2001. 